\title{
Prostate Cancer in Young Adults: About Two Cases at the Urology Department of the University Teaching Hospital of Point $\mathrm{G}$
}

\author{
Mamadou Lamine Diakité ${ }^{1}$, Falaye Sissoko ${ }^{1}$, Amadou Kassogué ${ }^{2 *}$, Salia coulibaly ${ }^{3}$, Cheickna \\ Badiaga $^{1}$, Aissata Samassekou ${ }^{1}$, Lanseni Doumbia ${ }^{1}$, Honoré Berthé ${ }^{1}$, Aly Tembely ${ }^{1}$ \\ ${ }^{1}$ Urology Department of the University Teaching Hospital of Point G, Mali. \\ 2,*Urology Department of the University Teaching Hospital Pr Bocar Sidy Sall of Kati, Mali. \\ ${ }^{3}$ Radiology Department of the University Teaching Hospital Pr Bocar Sidy Sall of Kati, Mali. \\ *Corresponding Author: Dr. Amadou Kassogué, Urology Department of the university teaching hospital Pr Bocar \\ Sidy Sall of Kati, Mali.
}

\begin{abstract}
We report two cases of prostate cancer in young adult 35 and 45 years old. Patients reported voiding disorders. On digital rectal examination, the prostate was hard. PSA levels were high. At the time of diagnosis, in two cases, there was an invasion of neighboring organs. Histology of the prostate biopsy confirmed adenocarcinoma of the prostate. We performed hormone therapy in two patients. The outcome was unfavorable in the first patient with death 6 months after the start of treatment. In the second patient, the clinical and biological evolution were good at 6 months and 1 year.
\end{abstract}

Keywords: Prostate cancer, young adults, hormone therapy

\section{INTRODUCTION}

Prostate cancer is a disease of older men. It is rare before the age of 50. In young adults, this tumor is most often very aggressive. The diagnosis is generally late, because it is discovered at an advanced clinical stage with a poorly differentiated histological type. Treatment is most often palliative and the prognosis is poor [1]. We report here two cases of adenocarcinoma of the prostate in young adults, 35 and 45 years old, respectively, in the urology department of the Point $G$ university hospital.

\section{Observation 1}

M.D, 35 years old man, referred by the nephrology department for bilateral ureterohydronephrosis on prostatic hypertrophy. He had a history of urinary schistosomiasis in childhood. There was no known family history of prostate cancer. He had a notion of dysuria, disabling pollakiuria and intermittent total hematuria evolving for 7 months, prompting several consultations and unsuccessful treatment with praziquantel.

On digital rectal examination, the prostate was increased in volume estimated at $70 \mathrm{~g}$, with an irregular contour, hard and painless. Kidney-bladder and prostate ultrasound revealed heterogeneous nodular prostatic hypertrophy with an estimated weight of $60 \mathrm{~g}$. The post voiding residue was estimated at $172 \mathrm{ml}$. Uro-CT revealed invasion of the seminal vesicles and bladder with bilateral stage III ureterohydronephrosis.

The PSA was $6.27 \mathrm{ng} / \mathrm{ml}$. The ECBU was negative. The serum creatinine was $167 \mathrm{umol} / \mathrm{l}$ and the hemoglobin level was $11.4 \mathrm{~g} / \mathrm{dl}$. The result of the biopsy prostate confirmed an adenocarcinoma of the prostate with a Gleason score of $7(4+3)$. After failure of the trans urethral catheterization attempt, suprapubic catheterization was performed.We classified the tumor as T4N0M0. We opted for hormonal therapy, because of the young age the patient, the locally advanced stage 
Prostate Cancer in Young Adults: About Two Cases at the Urology Department of the University Teaching Hospital of Point G

of the tumor. The patient refused surgical castration, patient received anti-androgen based on cyproterone acetate (50mg): 2 tablets morning and evening. The clinical course was favorable two months after initiation of this treatment and the lost sight of. The patient died 6 months later.

\section{Observation 2}

M. AD, 45 years old man, who was referred to us a clinic in Bamako, for heterogeneous prostatic hypertrophy on ultrasound. He had a history of urinary schistosomiasis in this childhood who was treated medically. He had no known family history of prostate cancer. On interrogation, he had a long history of dysuria, pollakiuria, and urination burns. The physical examination found fair general condition and chronic bladder retention prompting the placement of a suprapubic tube after failure of trans urethral catheterization. On digital rectal examination, the prostate was very enlarged, irregular and hard.

Kidney-bladder and prostate ultrasound revealed heterogeneous prostatic hypertrophy with an estimated weight of $123 \mathrm{~g}$ of suspicious appearance, moderate bilateral ureterohydronephrosis. The PSA level was $241 \mathrm{ng} / \mathrm{ml}$. The ECBU was negative. The result of the prostate biopsy confirmed an adenocarcinoma of the prostate with a Gleason score of $8(4+4)$. Thoraco-abdominal-pelvic computed tomography revealed invasion of the seminal vesicles, bladder and bilateral stage II ureterohydronephrosis. The tumor was classified as T4N0M0. We performed surgical castration (bilateral pulpectmy) after patient consent. The clinical and biological course was good at 6 monts and 1 year.

\section{DISCUSSION}

Prostate cancer is a rare tumor before the age of 50, with a frequency that does not exceed 1\% [1]. The average age at diagnosis is currently 70 years [2]. Our observations focused on patients aged 35 and 45 years old, respectively. The family history, being a risk factor for prostate cancer; recommending individual screening from the age of 45 , we have not found it in any of the cases observed. Damage at young age is not very symptomatic, and most often manifests itself in the late stage [3]. The diagnosis can be made in the presence of functional urinary signs, which are most often obstructive, as is the case in our two observations. But also, in front of signs of bone or lymph node metastases.

Imaging examens are unremarkable compared to other prostate tumors [4]. The PSA dosage is usually normal even in the presence of metastases because of the little differentiation of the tumor [3-6]. In our case, for observation 1 had a PSA of $6.27 \mathrm{ng} / \mathrm{ml}$, despite the locally advanced stage of the tumor. The same observation was made in a similar study in Tunisia, finding a PSA of $0.94 \mathrm{ng} / \mathrm{ml}$ for an adenocarcinoma of the prostate with Gleason $10(5+5)$ [4]. Very few cases are described in the literature. However, for the rare cases reported, the therapeutic option is most often palliative (hormone therapy, radiotherapy, chemotherapy), because of the advanced stage of the tumor at the time of diagnosis and the aggressiveness, given the young age of the patients. The modalities of these therapeutic methods in this entity given the rarity of cases have not yet been well codified [4].

However, radical prostatectomy has been reported for an adenocarcinoma of the prostate located in a young adult of 29 years [3]. Radical curative treatment can therefore be offered when indicated. The elements of good prognosis which can influence survival are asymptomatic character a time of diagnosis, good tumor differentiation on histology and response to hormonal treatment $[3,6,8]$. In our two patients, despite the absence of secondary localizations, the was an obstructive urinary symptomatology (bilateral obstructive ureterohydronephrosis) and the histological examination had found a poorly differentiated tumor with a Gleason $7(4+3)$ for the first and a gleason $8(4+4)$ for the second case.

The mean survival in the literature varies from 6 months $[3,5]$ to 12 months $[1,6]$. Two months after the start of treatment, we lost sight of the patient in observation 1 , thus limiting our follow-up. We learned of his death 6 months later. The patient in observation 2 had a good outcome after bilateral pulpectomy up to 1 year follow-up. According to the study by Bleyer and al. [9], the overall 5-years relative survival rate in the United States for men diagnosed between the ages of 40 and 80 was between $95 \%$ and $100 \%$, it was $80 \%$ in those aged 25 to 34 . Hussein and al. [10], reports 
Prostate Cancer in Young Adults: About Two Cases at the Urology Department of the University Teaching Hospital of Point G

that, ethnic, familial and genetic factors play a role in the early onset of prostate cancer, but the biology, especially of low grade prostate cancers detected at a young age, is not well understood.

The study of Salinas AC and al. [11], shows that among men with high-grade and advanced prostate cancer, those diagnosed at a young age have a higher causespecific mortality. He reports that this finding suggests that there are importantbiological differences between early-onset prostate cancer and late-onset cancer.

\section{CONCLUSION}

adenocarcinoma of the prostate in young adult is a rare and very aggressive tumor, diagnosed late with a histological type most often poorly differentiated. The treatment is palliative, given the advanced stage of the tumor when it is discovered. The prognosis is pejorative with survival generally not exceeding 6 months.

\section{REFERENCES}

[1] Tjaden HB, Culp DA, Flocks RH: Clinical adenocarcinoma of the prostate in patients under 50 years of age. J. Urol., 1965 ; 93 : 618-621.

[2] Rozet F, Hennequin C, Beauval JB, Beuzeboc $\mathrm{P}$, Cormier L, Fromont-Hankard G, $\mathrm{P}$ et al. : Recommandations françaises du comité de cancérologie de l'AFU pour le cancer de la prostate - actualisation 2018-2020: Cancer de la prostate, Prog. Urol. 2018 ; 28(12) : 79-130.

[3] Briet S, Tremeaux JC, Piard F, Striffling V: Adénocarcinome de la prostate de l'adolescent et l'adulte jeune. A propos d'une observation chez un homme de 20 ans. J. Urol. 1986 ; 92 : 565568.
[4] Sfaixi M, Miladi M, Bacha K, Zermani R., Chebil M, Ayed M : Cancer de la prostate de l'adulte jeune. Prog. Urol., 2003; 13: 313-315

[5] Hidenberg HB, Moul JW, Mostofi FK, McLeod DG : Clinically detected carcinoma of the prostaate treated by radical prostectomy in 29-year-old man. J. Urol, 1994 ; 152 : 966-967.

[6] Petit J, Kuss R, Abourachid H : Le carcinome prostatique avant trente ans. A propos de deux observations. Ann. Urol., 1981; 15 : 412-415.

[7] Sakr WA, Hass GP, Cassin BF, Pontes JE, Crissman JD. : The frequency of carcinoma and intraepithelial neoplasia of the prostate in young male patients. J. Urol. 1993; 150 : 379-385.

[8] Weitzner S, Sarikaya H, Furness TD: Adenocarcinoma of prostate in a twenty-sevenyear-old man. Urology, 1980; 16 : 286-288.

[9] Bleyer A, Spreafico F, Barr R. Prostate cancer in young men: An emerging young adult and older adolescent challenge. Cancer 2020; 126;(1): 4676.

[10] Hussein S, Satturwar S, Van der Kwast T. Youngage prostate cancer. J Clin Pathol 2015; 68: 511515.

[11] Salinas AC, Tsodikov A, Ishak-Howard M, Cooney KA. Prostate cancer in young men: an important clinical entity.Nat Rev Urol 2014;11(6): 317-23.

Citation: Mamadou Lamine Diakité, Falaye Sissoko, Amadou Kassogué, et al. Prostate Cancer in Young Adults: About Two Cases at the Urology Department of the University Teaching Hospital of Point G. Archives of Urology. 2021; 4(1): 15-17. DOI: https://doi.org/10.22259/2638-5228.0401004

Copyright: (c) 2021 Mamadou Lamine Diakité, Falaye Sissoko, Amadou Kassogué, et al. This is an open access article distributed under the Creative Commons Attribution License, which permits unrestricted use, distribution, and reproduction in any medium, provided the original work is properly cited. 